\title{
Potential technical hazards associated with four North American carbon capture and sequestration projects
}

\section{Mirhamed Sarkarfarshi, Chris Ladubec and Robert Gracie}

Department of Civil and Environmental Engineering, University of Waterloo, 200 University Ave W, Waterloo, ON N2L 3G1, Canada Email: sarkarfarshi@gmail.com Email: chris.ladubec@gmail.com Email: rgracie@uwaterloo.ca

\section{Maurice B. Dusseault*}

Department of Earth and Environmental Sciences, University of Waterloo, 200 University Ave W, Waterloo, ON N2L3G1, Canada Email: mauriced@uwaterloo.ca

*Corresponding author

\section{William Leiss}

McLaughlin Centre for Population Health Risk Assessment, Faculty of Medicine, University of Ottawa, 600 Peter Morand, Ottawa, Ontario, K1G 3Z7, Canada Email: wleiss@uottawa.ca

\section{Daniel Krewski}

\author{
McLaughlin Centre for Population Health Risk Assessment, \\ Faculty of Medicine, \\ University of Ottawa, \\ 600 Peter Morand, Ottawa, Ontario, K1G 3Z7, Canada \\ and \\ School of Epidemiology and Public Health, \\ Faculty of Medicine, \\ University of Ottawa, \\ 600 Peter Morand, Ottawa, Ontario, K1G 3Z7, Canada \\ and \\ Risk Sciences International, \\ 251 Laurier Avenue West, Suite 700Ottawa, ON K1P 5J6, Canada \\ Email: dkrewski@uottawa.ca
}


Abstract: Carbon capture and storage (CCS) risks depend upon the site geology, potential $\mathrm{CO}_{2}$-caprock reactions, anthropogenic pathways (legacy wellbores), and well construction and operation. Herein, we assess the major risks, termed 'georisks', acknowledging that quantitative description must be site-specific, although pathway impact generalisations are possible. We discuss geological and pathway issues to guide general site selection practices to reduce georisks. Events that trigger hazards and the consequences are presented for leakage, low storage capacity/injectivity, the release of hazardous gases and materials, surface uplift, and Induced seismicity. A supplementary literature-sourced hazard tabulation was developed with focus on four largescale North American CCS projects (Quest Project, Weyburn Project, Project Pioneer and FutureGen). Each hazard is classified based on the project phase and trigger activity. The risks of $\mathrm{CO}_{2}$, brine, or other fluid leakage through wells (injection, monitoring, decommissioned legacy wells) remain uncertain, but legacy well gas leakage is common, rather than exceptional, despite modern cementing and completion practices.

Keywords: carbon sequestration; carbon dioxide; risk; georisk; hazard; carbon capture and storage; CCS; leakage; seismic activities; surface uplift; containment.

Reference to this paper should be made as follows: Sarkarfarshi, M., Ladubec, C., Gracie, R., Dusseault, M.B., Leiss, W. and Krewski, D. (2019) 'Potential technical hazards associated with four North American carbon capture and sequestration projects', Int. J. Risk Assessment and Management, Vol. 22, Nos. 3/4, pp.359-383.

Biographical notes: Mirhamed Sarkarfarshi completed his $\mathrm{PhD}$ in 2015 at the University of Waterloo on the topic of Carbon Sequestration: Uncertainty and Parameter Estimation. He is currently employed within the finance industry.

Chris Ladubec completed his $\mathrm{PhD}$ in 2016 at the University of Waterloo on the topic of computationally efficient extended and stabilised finite element methods for multiphase carbon sequestration modelling. He is currently employed with the National Research Council of Canada.

Robert Gracie is an Associate Professor with the Department of the Civil and Environmental Engineering at the University of Waterloo (UW). He completed his $\mathrm{PhD}$ at Northwestern University on the simulation of deformation and fracture of solids in 2009, prior to which he spent two years with Natural Resources Canada conducting analysis of the interactions between ice, soil, and offshore pipelines. At UW, he carries out research in the development of numerical methods to simulate the deformation and fracture of solids and the flow of fluids. He is known for his work on the development and application of the Extended Finite Element Method (XFEM), which has been developed specifically to simulation fracture, dislocations, and multiphase flow. He has 33 journal articles on related topics. His current research interests include developing new simulation technologies for multiphase-phase flow during carbon sequestration and for hydraulic fracturing.

Maurice B. Dusseault is a Professional Engineer teaching Geological Engineering at the University of Waterloo since 1982, having graduated from the University of Alberta in 1977. His first five years in Edmonton were in a government-funded research and teaching chair. He carries out research in deep underground engineering issues including oil production, hydraulic fracturing, energy storage, geothermal energy, carbon sequestration, and deep injection disposal of granular solids and liquid wastes (including biosolids, oilfield 
wastes, and civil wastes). He holds over 90 international patents and has about 600 full-text papers published in journals and conferences. Maurice has served on major public panels, advised industry and government, and has graduated about $100 \mathrm{MSc}$ and PhD students in his career

William Leiss is a Fellow and Past-President (1999-2001) of the Royal Society of Canada and an Officer in the Order of Canada. From 1999 to 2004, he held the NSERC/SSHRC Research Chair in Risk Communication and Public Policy in the Haskayne School of Business, University of Calgary. From 1994 to 1999, he held the Eco-Research Chair in Environmental Policy at Queen's University, Kingston, Ontario. His earlier academic positions were in political science (Regina, York), sociology (Toronto), environmental studies (York), and communication (Simon Fraser). At Simon Fraser, he was also Vice President, Research. He is author, collaborator or editor of 15 books and numerous articles and reports, and for the past 20 years he has been a frequent consultant to government agencies and the private sector on risk management issues.

Daniel Krewski is a Professor in the School of Epidemiology, Public Health and Preventive Medicine at the University of Ottawa, where he also serves as Scientific Director of the McLaughlin Centre for Population Health Risk Assessment. He also serves as Chief Risk Scientist for Risk Sciences International, which works in partnership with the University of Ottawa. His research interests include epidemiology, biostatistics, risk assessment, and risk management. He is a fellow of the Society for Risk Analysis, the American Statistical Association, and a National Affiliate of the US National Academy of Sciences. He holds the Natural Sciences and Engineering Research Council of Canada Chair in Risk Science at the University of Ottawa.

\section{Introduction}

Carbon capture and storage (CCS) appears to be a technically feasible solution for reducing anthropogenic atmospheric $\mathrm{CO}_{2}$ emissions, thus reducing risks associated with global warming and climate change (IPCC, 2005). CCS can help bridge the existing technology gap between the dominant current energy production methods $(84 \%$ fossil energy-based methods) (British Petroleum, 2018) and less carbon-intensive solutions based on nuclear, geothermal, and renewable energy sources (Ebigbo et al., 2007). Indeed, it is widely argued that CCS will be obligatory (Bourzac, 2017) to meet COP 22 goals (Bodansky, 2016) of a moderate limit on mean global temperature increase $\left(\sim 2^{\circ} \mathrm{C}\right)$.

Risk assessment and management are essential elements of CCS project planning (Kopp et al., 2010; Walton et al., 2004) and are of key concern to the public, policy makers, and scientists (Seto and McRae, 2011). As part of an effective CCS risk assessment and management framework (Larkin et al., 2019c, 2019d), one early step is to gain comprehensive knowledge of hazards, hazardous event probability, and hazardous event consequences. Moreover, understanding the hierarchy of triggers and consequences of hazardous events is needed for choosing risk management strategies to reduce occurrence probability or to mitigate adverse consequences. In addition, failure scenarios encompassing feature, events, processes (FEPs) must be evaluated to complete a full risk assessment (Quintessa, 2012).

Generic databases of potential CCS hazards and their hierarchies exist (Le Guénana et al., 2011; Quintessa, 2012; Wilday et al., 2009, 2011), some focusing 
on specific types of hazards such as - environmental hazards (Barros et al., 2012), some investigating various hazards of a single technical aspect of CCS transportation or storage (URS, 2009). Nevertheless, placing realistic quantitative bounds on event probability and consequence remains a highly contentious process for several reasons, mainly because of a lack of experiential history in the area of georisk, critically important for long-term security. Larkin et al. (2019a, 2019b) discuss findings from a structured expert elicitation on relative risk and uncertainty judgements for potential hazards in injection and storage, and risk management of low probability high impact events.

The goal of this manuscript is to broadly catalogue some potential geo-hazards associated with actual CCS projects and present illustrative examples of the hierarchy of triggers and consequences, as well as qualitatively describe the probability and magnitude of their adverse consequences in a potential large-scale CCS site. This work contributes to hazard identification and characterisation in CCS risk assessment and management frameworks (Leiss, 2009). Although this article is limited to a discussion of potential technical hazards associated with four North American CCS projects - two operational and two planned - risk management actions that might be contemplated to address such hazards are discussed by Larkin et al. (2019c).

A CCS GeoRisk Database was created to classify potential hazards associated with CCS, including their consequences and occurrence probability. In addition to various international standards and publications, documents and reports from the following CCS projects (not all executed) have been used to populate the database: Shell QUEST Project (Canada); Project Pioneer (Canada); Weyburn Project (Canada); FutureGen Project (US) (Supplementary Material I). The potential technical hazards documented for these four CCS projects are intended to be illustrative, rather than exhaustive; additional technical risks may also be associated with CCS projects other than the four considered here. A discussion of toxicological risks is provided by Hillebrand et al. (2016). Risks associated with legal and economic issues are addressed in Anderson (2017). Risk assessment of carbon sequestration in the context of enhanced oil recovery is provided by Mocellin et al. (2018).

Each column in this potential hazard database contains one of the six major entities below:

1 Activity: hazardous events are classified into six major groups, based on the activity under which the event might occur:

a General: hazardous events such as spill of lubricants and antifreeze which might occur at any stage of the project.

b Capture: hazardous events such as degrading air quality, which might occur during the $\mathrm{CO}_{2}$ capture process.

c Transportation: hazardous events such as pipeline rupture, which might occur during the transportation process.

d Drilling: hazardous events such as contamination of groundwater with drilling fluid chemicals stored on the surface during the drilling process.

e Injection: hazardous events such as hydraulic fracture of the caprock which might occur during the injection period.

f Short-term storage: hazardous events such as massive leakage through undetected natural fractures in a short-term geostorage facility. 
$g$ Long-term storage: hazardous events such as leakage pathway development around decommissioned wellbores, which might occur in long-term storage.

2 Event: briefly describes the event deemed hazardous (the regulatory agency or advisory experts must define hazardous events).

3 Description: describes the event in more detail, accompanied by pointers to relevant references (documentation with name, pages, location) and data repositories.

4 Consequences: describes potential adverse consequences of the hazardous event, accompanied by pointers to relevant data and documentation.

5 Probability: describes the probability of the hazardous event, as given in references, accompanied by pointers to relevant data and documentation.

6 Magnitude: describes the magnitude of the hazard, as given in references, accompanied by pointers to relevant data and documentation.

In cases where no quantitative or qualitative probability or magnitude of a hazard is found in project site studies, these cells are left blank. Different references may be associated with one or more entries, so data from all references are used in the same order as the sources cited.

Figure 1 Structure of a bow-tie diagram (see online version for colours)

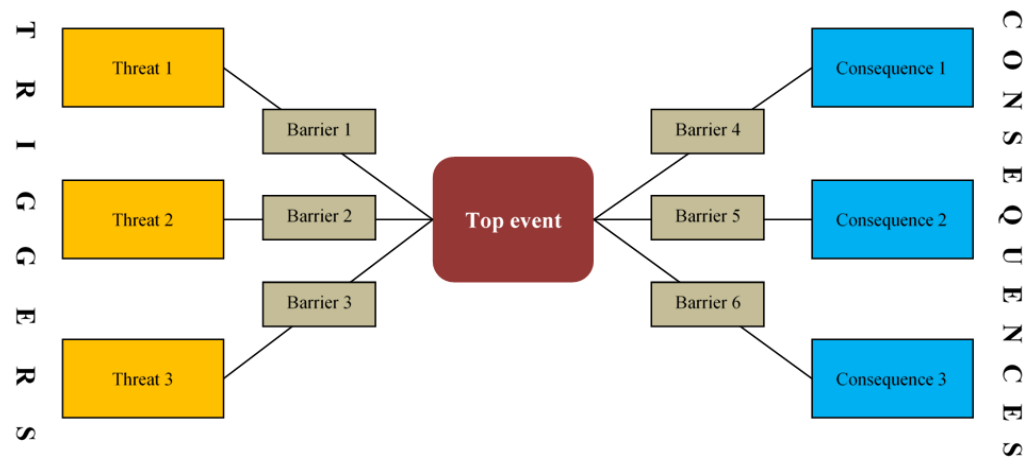

The database table establishes the hierarchy of events that triggers each hazardous event and the hierarchy of the consequences of the hazardous event. A 'bow-tie' diagram (Figure 1) can illustrate hierarchy relationships, risks and causal relationships among hazardous 'top event' threats, what 'triggers' the top event and the relevant 'consequences' (Gerstenberger et al., 2013). Operational practices that could serve as 'barriers' between the top event and the triggers, or between the event and consequences, can be included. These 'barriers' are actions that eliminate the threat, reduce its probability, or diminish the consequences in the CCS risk management system.

Here we will focus on the relationships between threats and consequences, but not the barriers, for six major hazardous events which may occur during carbon sequestration: 
1 leakage from the reservoir (loss or impairment of containment) during injection or storage

2 leakage of hazardous gases during transportation

3 unforeseen limitations in site storage capacity or well injectivity

4 release of hazardous materials, other than reservoir and pipeline leakage

5 unacceptable surface uplift

6 unacceptable or dangerous induced seismicity.

Section 2 is divided into six subsections, one for each the top event; the triggers and consequences to each event are decomposed into two levels to demonstrate corresponding causal relationships better. Summary and conclusion are provided in Section 3, and the hazard table is provided in the Supplementary Material I.

\section{Process overview and georisks}

In this section, we summarise the process of carbon sequestration and the associated georisks. Diagrams are presented to illustrate the causal relationship between triggers and the hazards, and between the adverse consequences of each hazard. Several constraints on the CSS parameters are introduced here to delimit the application domain, a necessary element in risk quantification and management. Emphasis is on georisks because these are the least understood and are subject to the greatest level of uncertainty.

Figure 2 Repository disposition and resulting pressure distribution (see online version for colours)

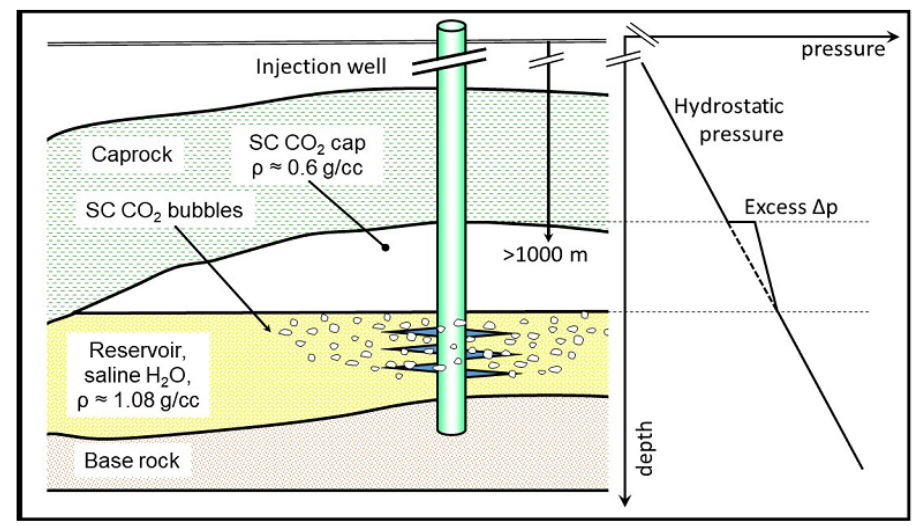

Herein, $\mathrm{CCS}$ is presumed to involve supercritical ( $\mathrm{SC}$ ) $\mathrm{CO}_{2}$ injection into saline aquifers (Figure 2), with the vast majority of the $\mathrm{SC} \mathrm{CO}_{2}$ rising to the structural top of the reservoir, forming a 'gas' cap, because its density is far less than the density of the formation brines. We limit the discussion to those cases where the $\mathrm{CO}_{2}$ is in a SC state 
under reservoir conditions. We note that there are other options such as direct biosolids injection (Dusseault, 2004), aqueous pre-dissolving of $\mathrm{CO}_{2}$ before or during injection (Dusseault and Malekzadeh, 2016), temporary sequestration in salt caverns (Dusseault et al., 2004), and mineral carbonation (Bachu et al., 1994). These alternate technologies possess risk profiles of their own, worthy of assessment (Bachu, 2000).

Although pure $\mathrm{CO}_{2}$ becomes a SC fluid at about $35^{\circ} \mathrm{C}$ and $7.2 \mathrm{MPa}$, it is possible (Figueroa et al., 2008), even likely in some capture technologies, that the $\mathrm{CO}_{2}$ stream is impure (with some $\mathrm{N}_{2}$ ) or becomes mixed with formation gases (such as $\mathrm{CH}_{4}$ ), thereby altering the supercritical point and other properties. Ongoing research suggests that impurities maybe be important factors in risk assessment of leakage from and transport within the reservoir (Brown et al., 2017). Hence, we assume that $10 \mathrm{MPa}$ is the pressure of the $\mathrm{SC} \mathrm{CO}_{2}$ in the reservoir, and in a hydrostatic pressure domain, this corresponds to a depth of about $950 \mathrm{~m}$ to $1,000 \mathrm{~m}$. We specify hydrostatic pressure conditions for the reservoir/repository because of additional risks of sequestration in over-pressured or under-pressured strata, and with the understanding that CCS will, for economic (wellbore costs) and several physical reasons (decreasing porosity and permeability with depth), likely occur at depths between one and 3 kilometres. This implies that a repository site will have wellbores of at least $1 \mathrm{~km}$ vertical depth accessing a saline aquifer of sufficient permeability and porosity to accommodate suitably large volumes of $\mathrm{SC} \mathrm{CO}_{2}$, on the order of $10^{6}$ tonnes/yr, or about $1.5-1.8 \times 10^{6} \mathrm{~m}^{3} / \mathrm{yr}$, over a 30 -year life. The depth and temperature conditions for a $\mathrm{SC} \mathrm{CO}_{2}$ repository are illustrated in Figure 3, although we note that if storage in the liquid phase was determined to be acceptable, a greater range of depth and temperature conditions would be possible (the boundary would expand in the direction of the black arrow). The arrow on the diagram indicates the direction of greater density of the fluid, and $\mathrm{CO}_{2}$ in its liquid state (not supercritical) is quite dense at low temperatures and high pressures. For example, at $10^{\circ} \mathrm{C}$ and $10 \mathrm{MPa}$, conditions that exist at depth in some permafrost areas and below the sea floor, liquid $\mathrm{CO}_{2}$ density is about 0.9 $\mathrm{g} / \mathrm{cm}^{3}$. Because buoyancy is a driving force for $\mathrm{CO}_{2}$ escape, the denser it is, the lower the escape risk, other factors being equal.

Figure 3 Supercritical $\mathrm{CO}_{2}$ repository conditions (see online version for colours)

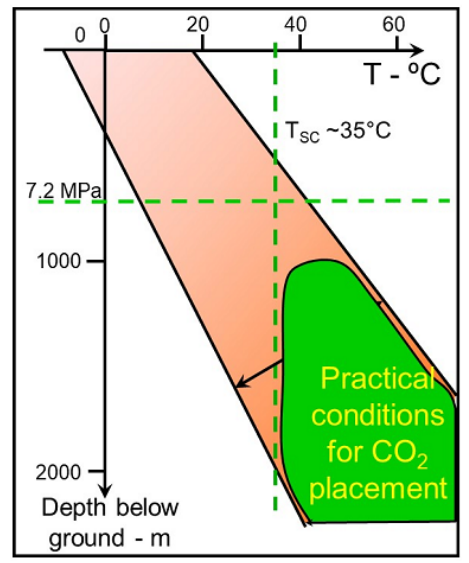




\subsection{Leakage (injection and storage)}

Assessing the risk of $\mathrm{CO}_{2}, \mathrm{H}_{2} \mathrm{~S}$, or brine leakage from the designated reservoir is the most challenging task in the broad evaluation of sequestration projects because many of the parameters remain poorly constrained until wells are drilled and tests done; even then, many uncertainties will remain. We believe that no matter how detailed the studies are, real projects will all have to be approached with a substantial reliance on adaptive management methods to mitigate the georisks (Williams et al., 2012; Linkov et al., 2006). Since the $\mathrm{CO}_{2}$ phase is extremely buoyant $\left(\rho_{\mathrm{CO} 2} \approx 0.6-0.8 \mathrm{~g} / \mathrm{cm}^{3}\right)$ compared to the reservoir resident fluid (for example, for saturated brine, $\rho_{\mathrm{w}} \approx 1.2 \mathrm{~g} / \mathrm{cm}^{3}$, any natural geological or induced faulting/fracturing of caprock can provide a pathway for upwards migration and leakage of the injected $\mathrm{CO}_{2}$. This condition will persist until all of the SC $\mathrm{CO}_{2}$ has dissolved into formation waters or reacted chemically. Furthermore, the low viscosity of $\mathrm{SC} \mathrm{CO}_{2}\left(\approx 1 / 20^{\text {th }}\right.$ that of formation water) means that any pathway will flow at $\approx 20 \times$ the volume rate of water under similar pressure gradient conditions.

Leakage of the brine into shallower aquifers due to pressure increase in the target reservoir is also possible (Dobossy et al., 2011; Newmark et al., 2010; MIT, 2012). However, brine leakage potential is small because of the large density difference between formation brines and fresh water. Because fluids seek equilibrium at the same fluid density elevation, displaced brines will tend to flow laterally, rather than vertically, if displaced by $\mathrm{SC} \mathrm{CO}_{2}$.

The various triggers leading to leakage, the numerous consequences of leakage, and the barriers which can mitigate risk are all of interest; the relationships among these triggers and consequences are illustrated in Figure 4. Although we mention $\mathrm{H}_{2} \mathrm{~S}$ leakage as a risk, and in many geological environments some $\mathrm{H}_{2} \mathrm{~S}$ may be present, in order to limit the complexity of this article, we do not discuss $\mathrm{H}_{2} \mathrm{~S}$-associated risks in detail. The major issue with $\mathrm{H}_{2} \mathrm{~S}$ is that it is poisonous in small concentrations, in contrast to $\mathrm{CO}_{2}$, which of itself is non-toxic.

Leakage pathways through the caprock (Figure 5) vary from naturally occurring imperfections [pre-existing fractures and non-sealing faults, locally highly permeable strata - Figure 5(d)], to induced imperfections (dissolution of minerals or hydraulic fracture), to manmade pathways (monitoring, injection, and legacy wells). Different reservoir configurations (Figure 5) must be considered, and different caprock lithologies will have different probabilities of natural pathway occurrence, varying from thick salt caprock with virtually no natural pathway [Figure 5(c)], to dense strata that have natural fractures that may or may not be largely closed under the ambient stresses at depth. Thermal stresses induced by the injection of $\mathrm{CO}_{2}$ at a lower temperature than that of the host reservoir $(\Delta T)$ can lead to opening of existing natural fractures or the creation of new ones for example induced fractures (Goodarzi and Settari, 2009). In addition, if the injection rate is high, the pressure in the reservoir could exceed the lateral stress (the fracture pressure), leading to the creation of induced hydraulic fractures and a reduction in the caprock integrity (Lavoie and Keith, 2010; Shell Canada Limited, 2010a, 2010c; US Department of Energy, 2013; Wilson and Monea, 2004). 
Figure 4 Illustration of triggers and consequences of $\mathrm{CO}_{2}, \mathrm{H}_{2} \mathrm{~S}$ or brine leakage out of the reservoir (see online version for colours)

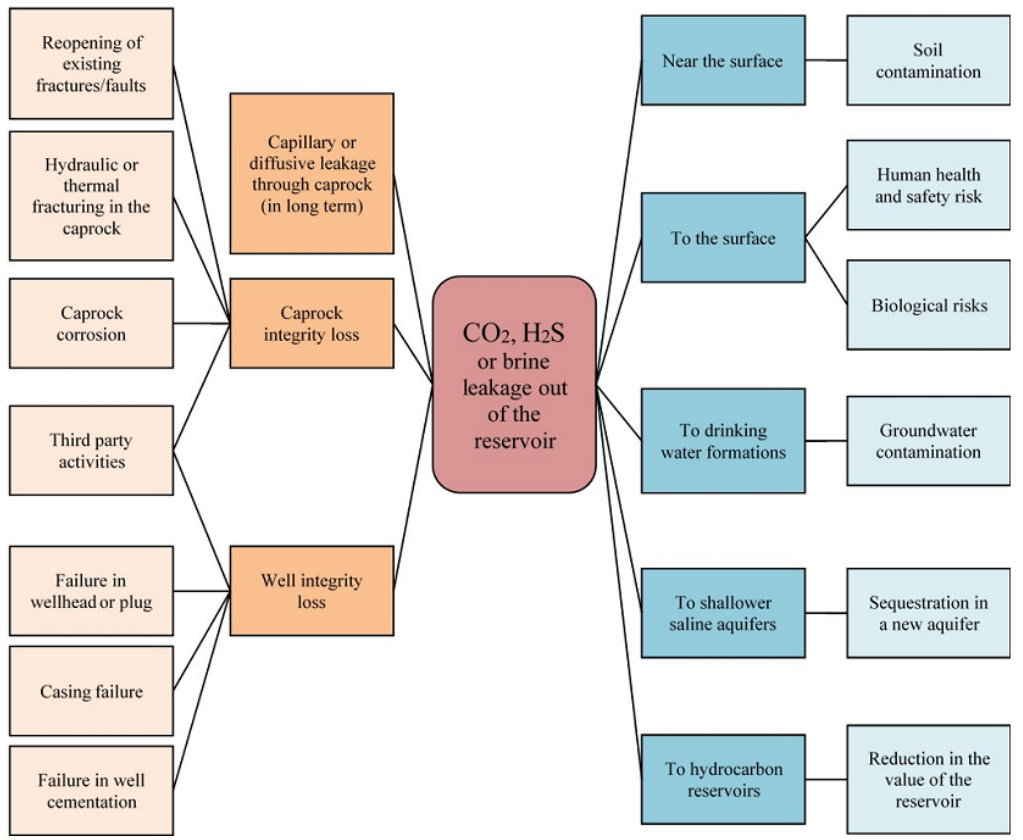

Figure 5 Geological variability in georisk assessment of $\mathrm{CO}_{2}$ escape, (a) structural trap

(b) lithostratigraphic trap (c) trapping by lateral extension of good caprock

(d) flow by buoyancy along permeable pathways (see online version for colours)

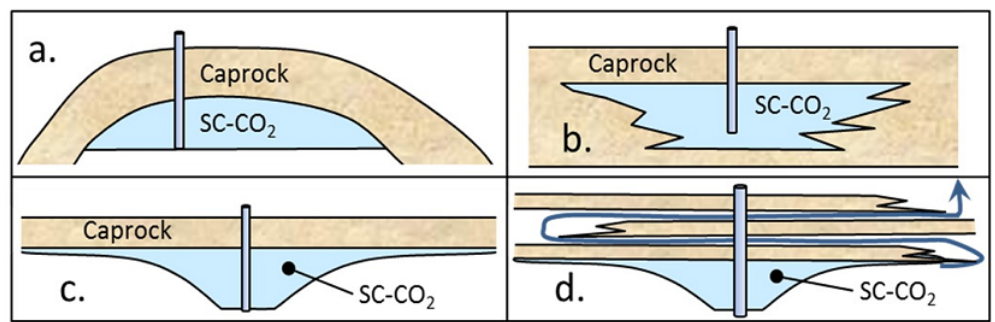


Additional processes that may lead to a condition of caprock hydraulic fracturing must be considered. If there is an appreciable temperature drop associated with the $\mathrm{SC} \mathrm{CO}_{2}$ injection, thermoelastic shrinkage will lead to a drop in the lateral stress in the reservoir, thermal conduction will propagate a cooler temperature into the caprock, arriving potentially at a condition where the injection pressure exceeds the lateral stress (Hojka et al., 1993). At that point, vertical hydraulic fractures can initiate, impairing the caprock seal. In general this would not be expected to occur because the process of injection can be carried out close to an isobaric condition, and the injectate T controlled to within a few degrees of the repository value.

The second condition is the development of a large vertical column of buoyant SC $\mathrm{CO}_{2}$ at the top of the reservoir (Figure 2). The equilibrated density of the $\mathrm{CO}_{2}$ can be as low as $0.6 \mathrm{~g} / \mathrm{cm}^{3}$ at a temperature of $40^{\circ} \mathrm{C}$ and a pressure of $10 \mathrm{MPa}$, whereas the density of the saline aquifer fluid will be in the range $1.05-1.10 \mathrm{~g} / \mathrm{cm}^{3}$ (as high as $1.2 \mathrm{~g} / \mathrm{cm}^{3}$ if the saline brine is $100 \% \mathrm{NaCl}$ saturated). Because the base of the $\mathrm{CO}_{2}$ column must be in pressure equilibrium with the regional hydrostatic pressure, the higher pressure at the top is equal to the height $(\Delta \mathrm{z})$ times the density difference $(\Delta \mathrm{p}=\Delta \rho \cdot \overline{\mathrm{g}} \cdot \Delta \mathrm{z})$. In normal fault stress environments where the lateral stress is intrinsically low, a combination of thermoelastic shrinkage and a large column of $\mathrm{CO}_{2}$ may lead to a breach of the caprock by induced fracturing. Of course, the combination of thermoelastic and density difference effects with a column of $\mathrm{SC} \mathrm{CO}_{2}$ represents a direct addition of the two effects, and if a vertical hydraulic fracture begins to propagate through the caprock, the critical condition has been reached because vertical propagation from density differences is a self-reinforcing process. In other words, we must unequivocally avoid reaching a critical breakthrough pressure at the top of the reservoir because fracture propagation and breakthrough would be almost certain.

If the caprock is salt $(\mathrm{NaCl})$, as in the case of the QUEST project in eastern Alberta, it is highly improbable that there are any through-going fractures because salt is self-healing over short times, and joints or faults do not persist as potential pathways. However, if the caprock is a shale or another competent rock where the matrix is essentially impermeable to a partially miscible liquid such as $\mathrm{SC}_{2}$, the only feasible vertical pathway is naturally existing fractures (joints, faults, fissures) of some discrete aperture (width). Because the natural fracture contains saline formation water, a capillary fringe will develop between the two fluids (Figure 6). Caprock integrity means that continuous pathways through the caprock do not exist or will not develop, so the capillary barrier must remain intact. Leaving aside second-order effects, the capillary pressure drop across the capillary front $\left(\Delta \mathrm{p}_{\mathrm{c}}\right)$ must be greater than the external pressure drop $\left(\Delta \mathrm{p}_{\mathrm{e}}\right)$ at the most restrictive aperture along the pathway for stability. Approximately, from Figure 2 and $6, \gamma / 2 \mathrm{r}>\Delta \rho \mathrm{g} \Delta \mathrm{H}$, where $\gamma$ is the surface tension of the capillary interface, $r$ is the radius of curvature of the interface (a function of wettability and aperture), $\Delta \rho$ is the density difference between the $\mathrm{SC} \mathrm{CO}_{2}$ and the saline aquifer water, and $\Delta \mathrm{H}$ is the height (Figure 6). The barrier quality of the capillary interface is clearly related to minimum aperture and the maintenance of a minimum surface tension. Processes that can increase the aperture (external stress changes, shale shrinkage, $\mathrm{CaCO}_{3}$ dissolution), reduce the surface tension, or increase $\Delta \mathrm{H}$ significantly are undesirable. 
Figure 6 Capillary barriers to vertical flow through fissures (see online version for colours)

saline aquifer water $-\rho \approx 1.1$

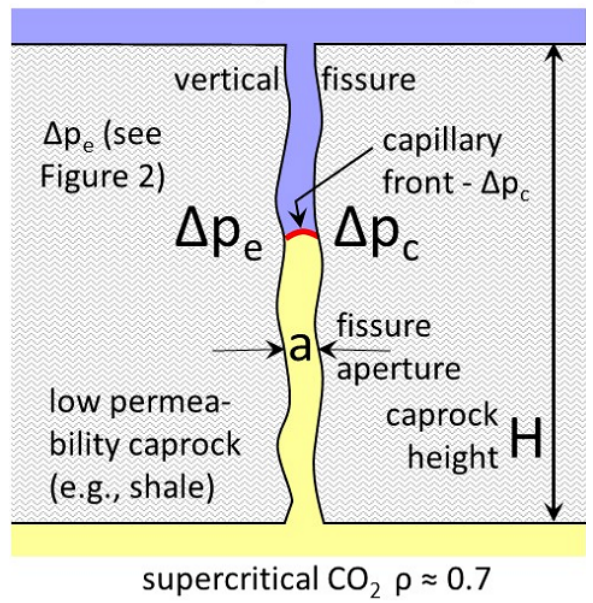

External forces such as earthquakes might also affect the caprock integrity through stress changes, or even creation of faulting and fracturing, which is why active seismic zones are not considered suitable for large volume sequestration (Zoback and Gorelick, 2012). Pore pressure changes from induced seismicity or earthquakes might also affect stresses, leading to reactivation of existing faults, slip along bedding planes, or significant reductions in the horizontal stresses in the caprock. Slip can lead to damage in cased wellbores (Dusseault et al., 2001) and impairments to caprocks providing pathways for migration of $\mathrm{CO}_{2}$ (DNV, 2012; Ghaderi and Leonenko, 2009; Nicot and Duncan, 2012; Preston et al., 2005; US Department of Energy, 2007; Wilson and Monea, 2004). $\mathrm{CO}_{2}$ can also diffuse through the caprock at a molecular level, regardless of the presence or absence of an interconnected pore space or a narrow-aperture natural fracture. However, this diffusion process is exceedingly slow and takes place over hundreds to thousands of years when free $\mathrm{CO}_{2}$ is available (Shell Canada Limited, 2010c, 2011a; Wilson and Monea, 2004). If the regional caprock is a continuous salt stratum or ductile shale without significant fracture pathways, we doubt that pure diffusion is a risk worthy of considering, in the context of other processes. It is well to remember that if very slow leakage is taking place, as long as the leakage is not accelerating it is most likely that the $\mathrm{CO}_{2}$ will dissolve into the unsaturated aquifer water and cease to exist as a separate buoyant phase, thereby greatly reducing risk.

$\mathrm{CO}_{2}$ will dissolve in the resident reservoir brine and acidify the water. The resulting weak acid (carbonic acid) can react with any carbonate minerals in the caprock and increase the overall permeability (Bai et al., 2015; Liu et al., 2012; Shell Canada Limited, 2010a, 2010c; US Department of Energy, 2007; Wilson and Monea, 2004), which may lead to $\mathrm{CO}_{2}$ or brine leakage (Shell Canada Limited, 2010c). This dissolution may take place in the matrix or along joints, but because of the increase in aperture of the flow pathway, it appears to be a self-reinforcing process similar to karstification (Kiraly, 2003) 
in most circumstances. Also, if $\mathrm{CO}_{2}$ is dissolved in saline aquifer water, its density is slightly greater than the original water, and this tends to suppress somewhat the vertical circulation of the acidified water. Because of these density differences arising during the dissolution process, the dissolution of carbonate minerals in the caprock is a particularly challenging density-reactivity coupled flow problem.

Because of the limited mutual solubility of $\mathrm{H}_{2} \mathrm{O}$ and $\mathrm{CO}_{2}$, a capillary fringe between the two fluids is maintained, but it is possible that high-porosity clay-rich caprock can be breached over time by shrinkage induced from small amounts of clay dehydration. In summary, if $\mathrm{CO}_{2}$ replaces the water adsorbed on clay particles, it will reduce the thickness of the adsorbed liquid layer, and potentially lead to a small amount of shrinkage. In the context of the capillary mechanism in Figure 6, if the aperture increases a small amount, the capillary resistance to flow reduces, increasing risk of breaching. Shrinkage also implies a loss of lateral stress, and this has additional implications for caprock integrity because it increases the risk of induced hydraulic fracturing.

Any reduction in the well integrity of injection, monitoring, or legacy wells can provide a pathway for $\mathrm{CO}_{2}$ leakage (Shell Canada Limited, 2010c; Nygaard, 2010; DNV, 2012; Ghaderi and Leonenko, 2009; US Department of Energy, 2007; Wilson and Monea, 2004; Nicot and Duncan, 2012; Preston et al., 2005). Acidified brine as well as pressure and temperature conditions can cause cement corrosion (Shell Canada Limited, 2011c; US Department of Energy, 2007), but if the cement corrosion is only because of diffusion, it would be too slow to be of consequence. Corrosion may become a problem if there is pressure driven advective flow arising from density differences (Figures 2 and 6). The presence of other chemicals in the $\mathrm{CO}_{2}$ stream (oxygen, hydrogen, etc.) may also lead to corrosion (DNV, 2012). Micro-annulus formation in the casing cement is another leakage pathway (Dusseault et al., 2000; Dusseault and Jackson, 2014; Shell Canada Limited, 2011a). Degradation of abandoned well cement can also occur in the presence of magnesium chloride (DNV, 2012; Wilson and Monea, 2004).

$\mathrm{CO}_{2}$ can affect elastomers used in the construction of wells. In addition, a reduction in pressure that is accompanied by a phase change can result in a temperature that could affect components used in wells construction, or take the form of the yielding or cracking of components due to temperature changes and the consequent thermal stresses (DNV, 2012; Lavoie and Keith, 2010). Well-head failure also provides a leakage pathway for $\mathrm{CO}_{2}$ (Shell Canada Limited, 2010a; US Department of Energy, 2007). It is worth mentioning here that third party activities (such as nearby hydraulic fracturing) might lead to loss of well integrity (Dusseault and Jackson, 2017; Preston et al., 2005; Shell Canada Limited, 2010c; Wilson and Monea, 2004).

Among the types of wells encountered in CCS projects, decommissioned wells have been the focus of several studies (Celia et al., 2005; Dobossy et al., 2011; Gasda et al., 2004; Humez et al., 2011; Kopp et al., 2010). Hundreds of thousands of oil and gas wells have been drilled in the past century in sedimentary basins such as Western Canadian Sedimentary Basin (WCSB), which is almost certainly the most-favoured region in Canada for implementation of large-scale CCS. For example, a sequestration site in the Viking formation in WCSB might encounter several hundreds of such wells (Gasda et al., 2004). Knowing the condition of these wells, especially the behind-the-casing region, is highly problematic.

Some of the legacy wells are undocumented, especially some of those drilled before a strong and consistent regulatory framework was established in the jurisdiction. For example, in the USA, it is estimated that there are on the order of 
150,000 undocumented wells (Cooley and Donnelly, 2012). Large numbers of undocumented wells exist in Ontario because of the early oil drilling developments before regulatory reporting, and many of these were not properly decommissioned. Furthermore, decommissioning standards have been improving for decades as more and more is understood about wellbore corrosion and cement/steel behaviour over time. Among the wells which have been properly decommissioned and are documented, the possibility remains of the degradation of the cement plugs within the abandoned steel casing and the adequacy of the initial cementation. Both of these can lead to pathway development over time, leading to the potential for near-wellbore leakage pathways for the injected $\mathrm{CO}_{2}$ (DNV, 2012; Wilson and Monea, 2004). These processes may involve buoyancy-driven issues, chemical effects (cement or steel deterioration), near-wellbore stress states, and fracture-driven flow (Dusseault and Jackson, 2014).

In Quest and FutureGen projects, the probability of leakage via abandoned wells was determined to be low or very low; however, future projects with less favourable geology will have to be planned carefully to consider the risks from unidentified or improperly decommissioned legacy wells.

The consequences of $\mathrm{CO}_{2}$ leakage depends on where it migrates. When leaking $\mathrm{CO}_{2}$ migrates into a shallower saline aquifer (beneath its own caprock) it may dissolve in the water, or it may be trapped through stratigraphic or structural trapping (Figure 5). In such cases, the $\mathrm{SC} \mathrm{CO}_{2}$ remains safely sequestered there and so does pose a significant risk - provided the integrity of the second caprock is not breached, and providing that a continuous vertical column of $\mathrm{CO}_{2}$ is not created (high buoyancy - Figure 2). The presence of multiple caprocks can thus reduce the risk of $\mathrm{CO}_{2}$ leakage in the long-term. In contrast, if leakage occurs into a shallower aquifer (providing potable water), the soil, or the atmosphere, then leakage can be a significant risk (Lawton et al., 2010) because of suffocation and aquifer impairment.

$\mathrm{CO}_{2}$ leakage into soil may lead to an increase in the soil acidity and introduce contaminants mobilised and transported by the passage of $\mathrm{CO}_{2}$ through the subsurface. $\mathrm{CO}_{2}$ leakage to the surface can also adversely affect the surface water, plants, animals and public health and safety (Shell Canada Limited, 2010a, 2010c, 2011a; US Department of Energy, 2007). In the case of significant leakage, the project's effectiveness at mitigating global warming is reduced (Shell Canada Limited, 2010c; Wilson and Monea, 2004).

Leakage pathways for $\mathrm{CO}_{2}$ can also allow leakage of brine, which can contaminate the drinking water (Nicot and Duncan, 2012; Nygaard, 2010). $\mathrm{H}_{2} \mathrm{~S}$ may also be present in the resident brine and can escape the aquifer via brine leakage (DNV, 2012; Ghaderi and Leonenko, 2009; Lavoie and Keith, 2010). According to the Alberta Environment Water Act, total dissolved solids in protected groundwater zone should be less than $4,000 \mathrm{mg} / \mathrm{L}$ (Shell Canada Limited, 2010c). $\mathrm{CO}_{2}$ or brine leakage into the groundwater can potentially violate this act. However, it is well to remember that brine is dense and it is not easy to displace dense brine upward through permeable strata containing less dense (fresher) water. The brine density favours lateral flow whenever such a pathway is available, and if brine encounters permeable strata during vertical migration, oil is unlikely to reach the surface. Nevertheless, in some circumstances such as around a wellbore, a 'gas lift' process can develop, lifting the brine toward the surface through reduction of the density of the water column by the incorporation of gas bubbles (Jackson and Dusseault, 2014). Figure 7 shows brine leaking from an old legacy well in Ontario because of an active gas lift taking place along the outside of the casing. 
Figure 7 Brine is being lifted to the surface by bubbling gas along the outer annulus (see online version for colours)

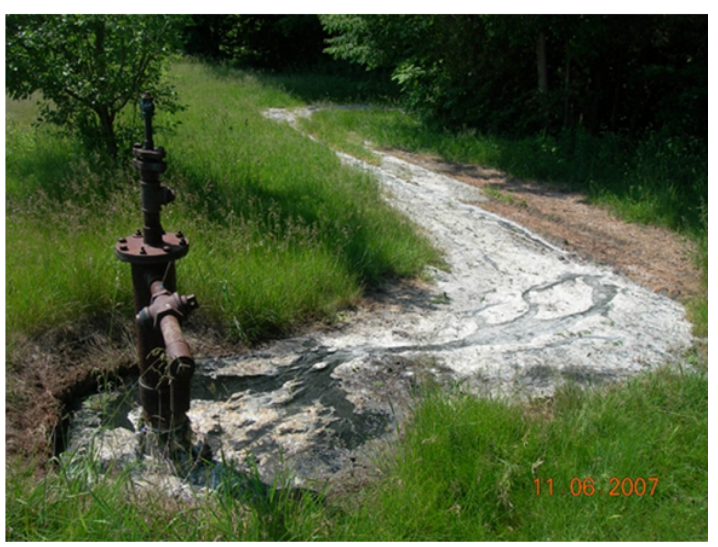

When leaking brine/ $\mathrm{CO}_{2}$ migrates into a shallower formation containing hydrocarbon resources the salinity or acidity of the hydrocarbon reservoir will increase which decreases the economic value of the hydrocarbon reservoir (DNV, 2012; Lavoie and Keith, 2010; Shell Canada Limited, 2010c, 2011c). Furthermore, leakage can also impact other activities conducted in shallower formations such as mineral mining, coal mining, and geothermal operations (DNV, 2012).

\subsection{Leakage during transportation}

There are several risks associated with the transportation of $\mathrm{CO}_{2}$ from a source (upgrader) to the sequestration site. A full evaluation of the risks of transportation is beyond the scope of this article; however, some of the risks associated with transportation of $\mathrm{CO}_{2}$ are presented here. It is possible to quantify transportation risks far better than the subsurface georisks discussed at greater length in the previous section. This is because subsurface processes are inherently difficult to quantify precisely and in part because many leakage cases remain unidentified [slow subsurface leakage of gas from legacy wellbores and inter-formation fluid flow through breached caprock (Dusseault, 2011)]. Hypothesising probabilities and consequences in the georisk sector is a far more contentious exercise than in the transportation sector where there are well-documented accident reports, case histories, and detailed autopsies (Barros et al., 2012). This said, risk assessment of leakage of $\mathrm{CO}_{2}$ from pipelines can be a non-trial task; for example, recent research demonstrates the importance of ground topology in the vicinity of a release event (Liu et al., 2017).

The transportation system is assumed to be composed of temporary storage tanks (above and/or below ground) at both the $\mathrm{CO}_{2}$ source and the CCS site and a pipeline from the source to the $\mathrm{CCS}$ site. The vectors leading to leakage of $\mathrm{CO}_{2}$ from transportation and consequences are summarised in Figure 8. 
Figure 8 Illustration of triggers and consequences of the release of $\mathrm{CO}_{2}$ and $\mathrm{H}_{2} \mathrm{~S}$ from transportation (see online version for colours)

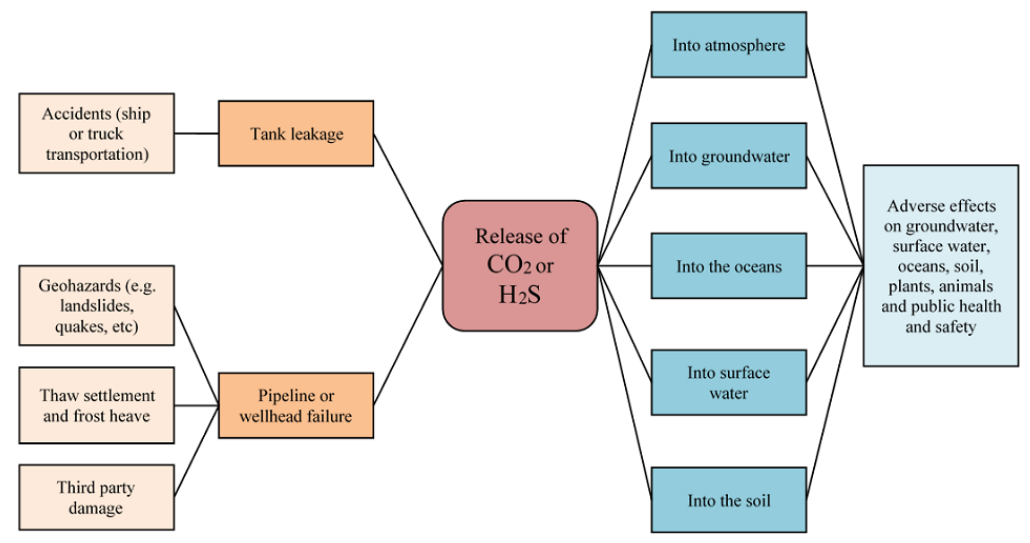

Failure in $\mathrm{CO}_{2}$ transportation pipelines may lead to release of $\mathrm{CO}_{2}$ into the atmosphere, surface water, groundwater, and soil (Shell Canada Limited, 2010a, 2011c; US Department of Energy, 2007). Various events such as geohazards (landslides and quakes), thaw settlement, frost heaves, and third-party damage can contribute to a pipeline failure (Barrie et al., 2005). Other transportation methods (truck or ship transport) are also subjected to specific risks of leakage due to various reasons such as accidents for trucks or sinking for ships. Probability of pipeline failure is site and project dependent; it varies with parameters such as pipeline specifications and route characteristics. For example, in the Quest project, the frequency of pipeline failure and wellhead failure are estimated as 0.00054 failures $/ \mathrm{km} / \mathrm{year}$ and 0.000136 failures/well/year, respectively (Shell Canada Limited, 2010a, 2011b, 2011c). In the FutureGen project, depending on site selection, pipeline rupture and puncture frequencies are listed unlikely or very unlikely: one occurrence in 100 to $1,000,000$ years and more than 1 occurrence in 100 to 1,000,000 years, respectively (US Department of Energy, 2007).

The magnitude of the consequences of pipeline or wellhead failure are dependent on variables such as pipeline specifications, route characteristics, leakage location, leakage rate, unattended leakage time and leakage detection technologies. For instance, the magnitude of consequences of pipeline failure in the Quest project is considered small due to Shell's early leakage detection system (Shell Canada Limited, 2011c). The effect of $\mathrm{CO}_{2}$ leakage on human health due to pipeline failure in the FutureGen project is assessed as small for all candidate sites. Pipeline failures occur regularly in Canada (Duncan and Wang, 2014); however, there is considerable industry experience managing these risks and regulatory oversight of pipelines is well established, so the risks associated with pipelines of any future CCS project would be expected to be acceptably low, and inherently manageable.

The risks associated with subsurface temporary storage of $\mathrm{CO}_{2}$, such as in salt caverns (Dusseault et al., 2004), have not been evaluated, but will have much in common with those of the primary sequestration site. 


\subsection{Low storage capacity and injectivity}

Lower than expected $\mathrm{CO}_{2}$ storage capacity or injectivity (ability to inject $\mathrm{CO}_{2}$ ) is a risk to both the economic viability and environmental benefit of a CCS project. In this section various risks related to low storage capacity and injectivity are discussed together with corresponding consequences. The relationship between the triggers and consequences is illustrated in Figure 9. Capacity estimates of the reservoir could have overestimated the true capacity. In that case, the $\mathrm{CO}_{2}$ would have no place to be stored (DNV, 2012) and there would be a significant loss of investment. Hence, storage capacity of a particular candidate for $\mathrm{CO}_{2}$ sequestration should be assessed carefully in the early stages of the project.

Figure 9 Illustration of triggers and consequences of low/impaired reservoir injectivity during a CCS operation (see online version for colours)

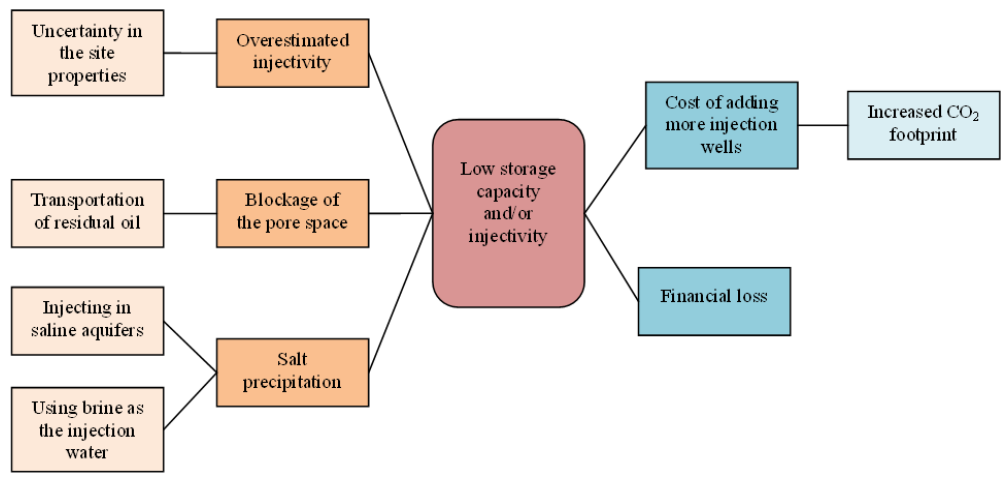

There is great deal of uncertainty in the estimation of reservoir permeability due to geological heterogeneity and spatial variability reasons. The placement of injection and production well within a heterogeneous field can have a large impact on system performance (Dewers et al., 2018). In the Quest project, the probability of having less than expected injectivity is reported as low, but not impossible (Shell Canada Limited, 2011c). If this is the case, then more wells will be needed in order to sustain the injection rate at the desired level (Shell Canada Limited, 2010c), meaning higher costs than initially estimated. Since in practice a minimum distance is required between the injection wells in order to avoid pressure interference, the $\mathrm{CO}_{2}$ injection domain can significantly increase leading to potential intersection of leakage pathways further away from the injection well, as implied in Figure 5(d) (Shell Canada Limited, 2010c).

Precipitation of salt around the injection well during geological $\mathrm{CO}_{2}$ sequestration in saline aquifers can lead to impairment of reservoir permeability and porosity leading to reduction in both injectivity and storage capacity. At the pore scale, precipitation of salt crystals takes place when $\mathrm{CO}_{2}$ dries out of the aqueous phase around the injection well [Figure 5(c)] causing salt blockage and impairment of the reservoir permeability and porosity (Kim et al., 2013; Puress and Garcia, 2002). In the Quest project, this is expected to occur within a small radius $(\sim 15 \mathrm{~m})$ from the injection well (Shell Canada Limited, 2011a), and the degree of pore blocking is likely to be small. When $\mathrm{CO}_{2}$ displaces 
formation brine, the water phase is expelled until it reaches the residual saturation state, which, depending on the permeability (grain size) of the reservoir, will be on the order of $20-30 \%$. It is only the $\mathrm{NaCl}$ remaining in this residual water that will eventually precipitate as the continuing flow of $\mathrm{CO}_{2}$ gradually strips away the water in an evaporative process. The probability of salt precipitation of operational consequence in the Quest project is viewed as low (Shell Canada Limited, 2011a). The same issues are highly likely in injection sites such as mature oil fields, where the mobilisation of the residual oil due to $\mathrm{CO}_{2}$ injection may reduce the injectivity through creation of blockage at pore level.

\subsection{Release of hazardous gases and materials}

This section focuses on risks related to release of hazardous gases and materials. The relationship between the triggers and consequences is illustrated in Figure 10.

Figure 10 Illustration of triggers and consequences of release of hazardous gases and materials (see online version for colours)

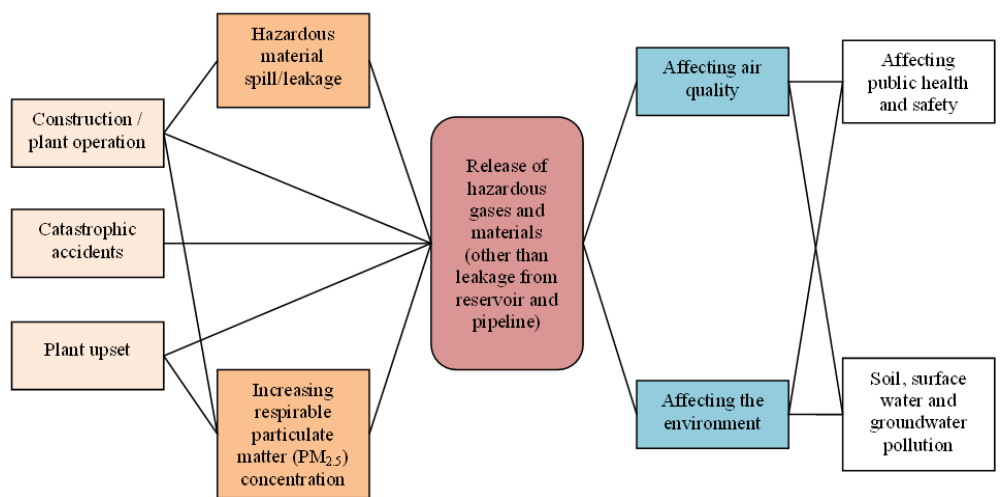

Various hazardous materials such as lubricants, antifreezes, drilling mud, and workover fluid containing toxic, flammable, or explosive components are used at various stages of a CCS project from construction to operation (Shell Canada Limited, 2010a). Any minor or major accident has the potential of spilling these materials. The probability and consequences of such spills depend on parameters such as the material type, material container, spill location, spill amount, etc. Such an event is assumed unlikely in Quest and FutureGen projects (Shell Canada Limited 2010a, 2011a; US Department of Energy, 2007) and relevant consequences are reported negligible in Quest project (Shell Canada Limited, 2011c) due to operational practices.

Catastrophic incidents such as plant explosion, attacks or sabotage can also cause release of hazardous gases such as $\mathrm{CO}, \mathrm{H}_{2} \mathrm{~S}$ and $\mathrm{SO}_{2}$ (US Department of Energy, 2007). Consequences of such events are completely dependent on the plant location, specifications, accident type, and magnitude, etc. In the FutureGen project for instance, the effect of catastrophic accidents on human health and safety is listed as 2 to 26 irreversible effects and 0 to 4 life threatening effects (exposure to $\mathrm{CO}$ ), 2 to 
19 irreversible effects and 1 to 10 life threatening effects (exposure to $\mathrm{SO}_{2}$ ), 12 to 143 irreversible effects and 0 to 4 life threatening effects (exposure to $\mathrm{H}_{2} \mathrm{~S}$ ) (US Department of Energy, 2007).

Emissions such as nitrogen dioxide $\left(\mathrm{NO}_{2}\right)$ and respirable particulate matter $\left(\mathrm{PM}_{2.5}\right)$ in various stages of the project can also adversely affect the air quality (Shell Canada Limited, 2010a, 2010b). Various consequences are expected in this scenario depending on exposure time, location, type, and concentration of the hazardous emissions. Cancer risk due to emissions during plant operation is estimated from $0.022 \times 10^{-6}$ to $0.222 \times 10^{-6}$ in the FutureGen project (US Department of Energy, 2007).

In the Quest project, consequences of $\mathrm{NO}_{2}$ and $\mathrm{PM}_{2.5}$ emissions during normal plant operation are determined to be negligible, except exposure to $\mathrm{NO}_{2}$ for people in the project site (Shell Canada Limited, 2010a). In the FutureGen project, maximum annual and $24 \mathrm{hr}$ increase in $\mathrm{PM}_{2.5}$ concentrations are listed as 0.038 and $0.524 \mu \mathrm{g} / \mathrm{m}^{3}$, respectively (US Department of Energy, 2007). It should be mentioned here that $\mathrm{PM}_{2.5}$ concentrations less than $5.8 \mu \mathrm{g} / \mathrm{m}^{3}$ are assumed to have no significant impact on human mortality rate, but any impact will affect health (Evans et al., 2013).

\subsection{Surface uplift}

In this section various risks related to surface uplift due to pressure build-up in the target reservoir are discussed together with corresponding consequences. The relationship between these triggers and consequences is illustrated in Figure 11.

Figure 11 Illustration of triggers and consequences of pressure induced surface uplift (see online version for colours)

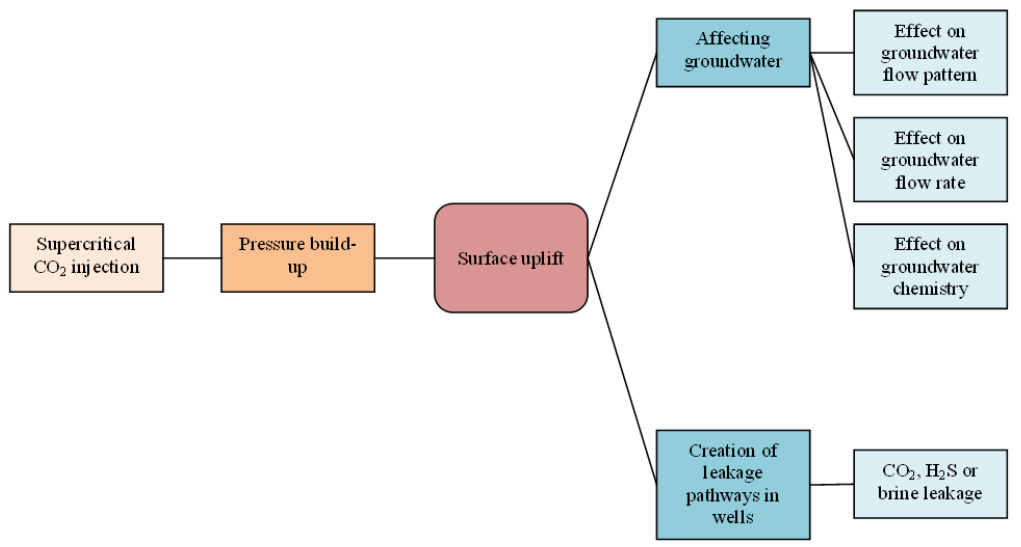

During the CCS operation, pressure build up in the reservoir takes place over time and depending on the formation injectivity and depth higher injection pressures may be needed in order to inject the $\mathrm{CO}_{2}$ with an acceptable injection rate. This process, especially in vicinity of the injection well, may lead to ground surface deformation (heave) (Shell Canada Limited, 2010c, 2011a; Nygaard, 2010; DNV, 2012) affecting the groundwater flow patterns, rate, and chemistry, or creating fractures which can serve as 
leakage pathways DNV, 2012; Nygaard, 2010; Shell Canada Limited, 2011a). Probability of ground surface heave is determined through geomechanical modelling to be low in Quest project with a maximum uplift of $60 \mathrm{~mm}$, which is deemed insignificant (Shell Canada Limited, 2010c).

\subsection{Induced seismicity}

Supercritical $\mathrm{CO}_{2}$ injection under high pressure can lead to induced seismic activities triggered by fault reactivation if such faults exist in the injection area (Quintessa, 2012). Pore pressure changes during the operation can lead to the reactivation of existing faults and triggering quakes which may damage the wellbores and the surface facilities in the project area (DNV, 2012; Mazzoldi et al., 2012; Verdon et al., 2010; Wilson and Monea, 2004). The deep disposal of waste water from hydraulic fracturing activities in Oklahoma, USA, has induced earthquakes up to 5.8 moment magnitude $\left(\mathrm{M}_{\mathrm{w}}\right)$ as recently as 2016 (Foulger et al., 2018). In Western Canada, hydraulic fracture activities have directly induced earthquake events at Fox Creek, Alberta (Atkinson et al., 2016). Experience with induced seismicity in the context of hydraulic fracturing suggests that predictions for the maximum magnitude of an induced event from a given project will be uncertain. Recent studies of large data sets of injection well data suggest that there is not a strong correlation between injected volume and maximum event magnitude. Induced seismicity risk in Alberta, Canada, is currently managed in part by a stop-light system, which sees injection rates reduced or injection ceased when seismicity is induced. However, since events are often recorded weeks or months after injection has stopped further mitigation strategies may need to be investigated in the future (Atkinson et al., 2016).

Figure 12 Illustration of triggers and consequences of induced seismicity (see online version for colours)

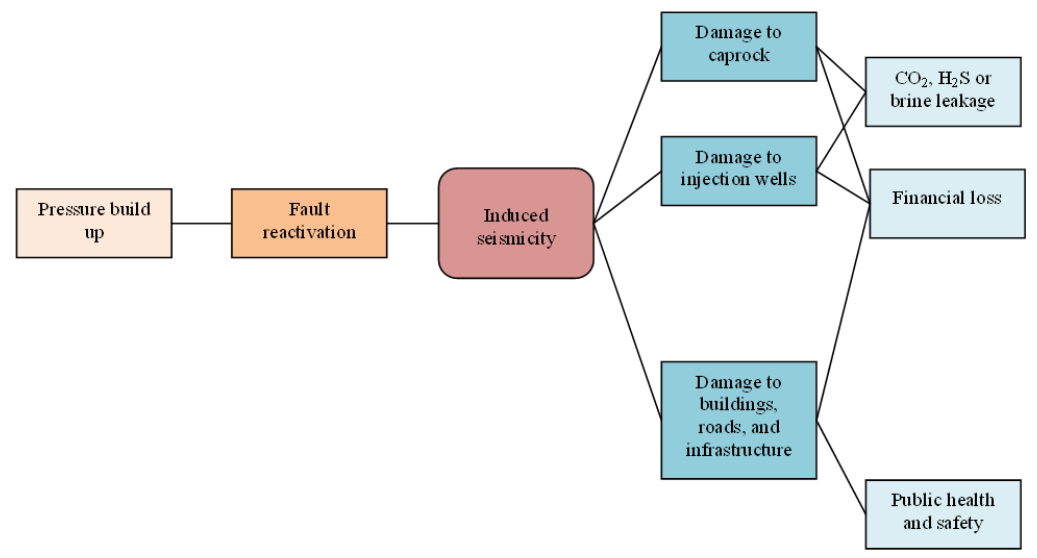

Note: Beyond these consequences, loss of social license is also possible. 
The relationship between the triggers and consequences is illustrated in Figure 12. The aforementioned damage to the wellbores and the surface facilities in the project area can cause $\mathrm{CO}_{2}, \mathrm{H}_{2} \mathrm{~S}$, or brine leakage and pose public safety risks in addition to impairing the economy of the project. Such events can be prevented through a proper geological study and monitoring of the CCS project and adopting a proper injection strategy in order to avoid excessive pressure buildup in the region.

\section{Summary and conclusions}

In this article, a review of the hazards associated with CCS, as reported in actual CCS projects, has been summarised. The hierarchy of triggers and consequences of the hazards and probability and magnitude of the hazards in all phases of CCS (capture, transport, injection and storage) were examined in large-scale CCS sites. The hazards associated with CCS are reviewed based on literature, with particular focus on four North American large scale CCS project studies (Quest Project, Weyburn Project, Project Pioneer and FutureGen). A hazards table is generated containing the phase of CCS and the activity which triggers the hazard, the probability and consequences of each hazard based on the aforementioned CCS site studies and the references (Supplementary Material I).

Based on the hazards table, a set of diagrams is developed and used to demonstrate the hierarchy of triggers and consequences of the hazards. These diagrams are useful for identifying where actions can be taken to avoid and/or mitigate the consequences hazardous event.

In addition, we want to highlight how good site selection can be a barrier to the hazards and consequences. The likelihood and consequences of the abovementioned leakage cases are dependent on both site location (leakage pathway characteristics and multiple caprocks) and operational practices (leakage detection time and monitoring). Geological features are perhaps the dominant factors controlling the technical and economic viability of the project. The high degrees of uncertainties and/or lack of sufficient geological and geomechanical data, especially in early stages of the site selection process, and the very limited number of successful field examples makes knowledge of the geology a major barrier to assessing suitability of a particular site and forecasting the efficiency of the operation in the mid- and long-term with a high degree of accuracy. For instance, overestimation of porosity and permeability of the target formation can lead to overestimation of formation storage capacity and injectivity which can make the project economy less attractive in addition to causing operational issues. A comprehensive and detailed geological and geomechanical assessment of the candidates for large-scale geological $\mathrm{CO}_{2}$ sequestration can reduce the risks significantly.

The potential hazards presented in this paper will serve as a guide for assessing the potential risks of this important technology and support the safe and effective deployment of large-scale CCS facilities. The hazards table can be refined, broadened, and updated as additional experience with CCS technology accumulates. For example, the potential hazards associated with induced seismicity and well leakage remain difficult to quantify at this time, though progress in this regard is being made. The framework and initial hazard taxonomy provided in this paper will provide a basis for further elaboration of potential risks associated with CCS technology, in support of effective CCS risk management practices. 
Supplementary Material I consisting of a table of hazards is available at the Harvard Center for Risk Analysis website (https://www.hsph.harvard.edu/hcra/).

\section{References}

Anderson, S.T. (2017) 'Risk, liability, and economic issues with long-term CO 2 storage - a review', Natural Resources Research, Vol. 26, No. 1, pp.89-112.

Atkinson, G.M., Eaton, D.W., Ghofrani, H., Walker, D., Cheadle, B., Schultz, R., Shcherbakov, R., Tiampo, K., Gu, J., Harrington, R.M. and Liu, Y. (2016) 'Hydraulic fracturing and seismicity in the Western Canada Sedimentary Basin.', Seismological Research Letters, Vol. 87, No. 3, pp.631-647.

Bachu, S. (2000) 'Sequestration of $\mathrm{CO}_{2}$ in geological media: criteria and approach for site selection in response to climate change', Energy Conversion and Management, Vol. 41, No. 9, pp.953-970.

Bachu, S., Gunter, W.D. and Perkins, E.H. (1994) 'Aquifer disposal of $\mathrm{CO}_{2}$ : Hydrodynamic and mineral trapping', Energy Conversion and Management, Vol. 25, No. 4, pp.269-279.

Bai, M.X., Sun J.P., Song, K.P., Reinicke, K.M. and Teodorin, C. (2015) 'Risk assessment of abandoned wells affected by $\mathrm{CO}_{2}$ ', Environmental Earth Sciences, Vol. 11, DOI: 10.1007/s12665-015-4163-7 [online] https://www.researchgate.net/publication/273520593_ Risk_assessment_of_abandoned_wells_affected_by_CO2 (accessed July 2018).

Barrie, J., Brown, K., Hatcher, P.R. and Schellhase H.U. (2005) 'Carbon dioxide pipelines: a preliminary review of design and risks', Proceedings of the 7th International Conference on Greenhouse Gas Control Technologies, September, Vancouver, Canada, Vol. 1, pp.315-320.

Barros, N., Oliveira, G.M. and Lemos de Sousa, M.J. (2012) 'Environmental impact assessment of carbon capture and sequestration: General overview', IAIA12 Conference Proceedings 32nd Annual Meeting of the International Association for Impact Assessment, Porto, Portugal, 6pp.

Bodansky, D. (2016) 'The Paris climate change agreement: a new hope?', American Journal of International Law, Vol. 110, No. 2, pp.288-319.

Bourzac, K. (2017) 'We have the technology. (News and editorial opinion article)', Nature, Vol. 550, No. 7675, pp.866-869.

British Petroleum (2018) BP Statistical Review of World Energy [online] https://www.bp.com/ content/dam/bp/en/corporate/pdf/energy-economics/statistical-review/bp-stats-review-2018full-report.pdf.

Brown, A., Eickhoff, C., Reinders, J.E.A., Raben, I., Spruijt, M. and Neele, F. (2017) 'IMPACTS: framework for risk assessment of $\mathrm{CO}_{2}$ transport and storage infrastructure', Energy Procedia, Vol. 114, pp.6501-6513.

Celia, M.A., Bachu, S., Nordbotten, J.M., Gasda, S.E. and Dahle, H.K. (2004) 'Quantitative estimation of $\mathrm{CO}_{2}$ leakage from geological storage: analytical models, numerical models, and data needs', Proceedings, 7th International Conference on Greenhouse Gas Control Technologies, Vancouver, Elsevier Science Ltd., pp.663-671.

Cooley, H. and Donnelly, K. (2012) Hydraulic Fracturing and Water Resources: Separating the Frack from the Fiction, Pacific Institute, Oakland CA, 25pp, ISBN: 1-893790-40-1.

Det Norske Veritas (DNV) (2012) Recommended Practice DNV-RP-J203, Geological Storage of Carbon Dioxide, April [online] https://rules.dnvgl.com/docs/pdf/DNV/codes/docs/201307/RP-J203.pdf (accessed 21 July 2019).

Dewers, T., Eichhubl, P., Ganis, B., Gomez, S., Heath, J., Jammoul, M. et al. (2018) 'Heterogeneity, pore pressure, and injectate chemistry: Control measures for geologic carbon storage', International Journal of Greenhouse Gas Control, January, Vol. 68, pp.203-215.

Dobossy, M.E., Celia, M.A. and Nordbotten, J.M. (2011) 'An efficient software framework for performing industrial risk assessment of leakage for geological storage of $\mathrm{CO}_{2}$ ', Energy Procedia, Vol. 4, pp.4207-4214. 
Duncan, I.J. and Wang, H. (2014) 'Estimating the likelihood of pipeline failure in $\mathrm{CO}_{2}$ transmission pipelines: new insights on risks of carbon capture and storage', International Journal of Greenhouse Gas Control, February, Vol. 21, pp.49-60.

Dusseault M.B., Bruno M.S., Barrera J. (2001) 'Casing shear: causes, cases, cures', Drilling and Completions Journal, Vol. 16, No. 2, pp.98-107, Society of Petroleum Engineers.

Dusseault, M.B. (2004) 'Deep biosolids injection: environmental protection with energy recycling and carbon sequestration', Proceedings, 3rd Asian Rock Mechanics Symposium, Millpress Science Publishers, Kyoto, Japan, 10pp.

Dusseault, M.B. (2011) 'Geomechanical challenges in petroleum reservoir exploitation', Korean Society of Civil Engineers Journal of Civil Engineering, Vol. 15, No. 4, pp.669-678.

Dusseault, M.B. and Jackson, R.E. (2014) 'Seepage pathway assessment for natural gas to shallow groundwater during well stimulation, in production, and after abandonment', Environmental Geosciences, Vol. 21, No. 3, pp.107-126.

Dusseault, M.B. and Jackson, R.J. (2017) 'Seepage pathways in hydraulic fracturing', Proc. GeoOttawa 2017. Proceedings, Annual Conference of the Canadian Geotechnical Society, Geotechnical Society, Ottawa ON. 8pp.

Dusseault, M.B. and Malekzadeh, F. (2016) Sequestration of Greenhouse Gasses by Generating an Unstable Gas/Saline front within a Formation, US Patent: US9316093B2.

Dusseault, M.B., Bachu, S. and Rothenburg, L. (2004) 'Sequestration of $\mathrm{CO}_{2}$ in salt caverns', Journal of Canadian Petroleum Technology, Vol. 43, No. 11, pp.49-55.

Dusseault, M.B., Gray, M.N. and Nawrocki, P.A. (2000) 'Why oilwells leak: cement behavior and long-term consequences', Proc. Society of Petroleum Engineers International Oil and Gas Exhibition and Conference, Beijing, China, SPE ${ }^{\#} 64733$.

Ebigbo, A., Class, H. and Helmig, R. (2007) ' $\mathrm{CO}_{2}$ leakage through an abandoned well: problem-oriented benchmarks', Computational Geoscience., Vol. 11, No. 2, pp.103-115.

Evans, J., van Donkelaar, A., Martin, R.V. et al. (2013) 'Estimates of global mortality attributable to particulate air pollution using satellite imagery', Environmental Research, January, Vol. 120, pp.33-42.

Figueroa, J.D., Fouta, T., Plasynski, S., McIlvried, H. and Srivastava R.D. (2008) 'Advances in $\mathrm{CO}_{2}$ capture technology - the U.S. Department of Energy's Carbon Sequestration Program', International Journal of Greenhouse Gas Control, Vol. 2, No. 1, pp.9-20.

Foulger, G.R., Wilson, M., Gluyas, J., Julian, B.R. and Davies, R. (2018) 'Global review of human-induced earthquakes', Earth-Science Reviews, Vol. 178, pp.438-514.

Gasda, S.E., Bachu, S. and Celia, M.A. (2004) 'Spatial characterization of the location of potential leaky wells penetrating a deep saline aquifer in a mature sedimentary basin', Environmental Geology, Vol. 46, Nos. 6-7, pp.707-720.

Gerstenberger, M., Christophersen, A., Buxton, R., Allinson, G., Hou, W., Leamon, G. and Nicol, A. (2013) 'Integrated risk assessment for CCS', Energy Procedia, Vol. 37, pp.2775-2782.

Ghaderi, S. and Leonenko, Y. (2009) Reservoir Modelling, Wabamun Area $\mathrm{CO}_{2}$ Sequestration Project (WASP), University of Calgary Institute for Sustainable Energy, Environment and Economy (ISEEE), Calgary.

Goodarzi, S. and Settari, A. (2009) Geomechanical Modelling and Analysis, Wabamun Area $\mathrm{CO}_{2}$ Sequestration Project (WASP), University of Calgary Institute for Sustainable Energy, Environment and Economy (ISEEE), Calgary.

Hillebrand, M., Pflugmacher, S. and Hahn, A. (2016) 'Toxicological risk assessment in CO2 capture and storage technology', International Journal of Greenhouse Gas Control, December, Vol. 55, pp.118-143.

Hojka, K., Dusseault, M.B. and Bogobowicz, A. (1993) 'Analytical solutions for transient thermoelastic stress fields around a borehole during fluid injection into permeable media', Journal of Canadian Petroleum Technology, Vol. 32, No. 4, pp.49-57. 
Humez, P., Audigane, P., Lions, J., Chiaberge, C. and Bellenfant, G. (2011) 'Modelling of $\mathrm{CO}_{2}$ leakage up through an abandoned well from deep saline aquifer to shallow fresh ground water', Transport in Porous Media, October, Vol. 90, pp.153-181.

International Panel on Climate Change (IPCC) (2005) International Panel On Climate Change: Special Report on Carbon Dioxide Capture and Storage, Prepared by working Group III of the Intergovernmental Panel on Climate Change, Cambridge University Press, New York, 442pp.

Jackson, R.E. and Dusseault, M.B. (2014) 'Gas release mechanisms from energy wellbores', Proc. 48th U.S. Rock Mechanics Symp, Minneapolis, Paper ARMA 14-7753, 5pp.

Kim, M., Sell, A. and Sinton, D. (2013) 'Aquifer-on-a-chip: understanding pore-scale salt precipitation dynamics during $\mathrm{CO}_{2}$ sequestration', Lab Chip, Vol. 13, pp.2508-2518; DOI: $10.1039 / \mathrm{C} 3 \mathrm{LC} 00031 \mathrm{~A}$

Kiraly, L. (2003) 'Karstification and groundwater flow', Speleogenesis and Evolution of Karst Aquifers, Vol. 1, No. 3, pp.155-192.

Kopp, A., Binning, P.J., Johannsen, K., Helmigc, R. and Classc H. (2010) 'A contribution to risk analysis for leakage through abandoned wells in geological $\mathrm{CO}_{2}$ storage', Advances in Water Resources, Vol. 33, No. 8, pp.867-879.

Larkin, P., Dusseault, M., Gracie, R.G., Sarkarfarshi, A.M., Shafiei, A., Aspinall, W. and Krewski, D. (2019a) 'Risk management in carbon capture and storage: insights from a structured expert elicitation', International Journal of Risk Assessment and Management, forthcoming.

Larkin, P., Dusseault, M., Gracie, R.G., Sarkarfarshi, A.M., Shafiei, A., Aspinall, W. and Krewski, D. (2019b) 'Uncertainty in risk issues for carbon capture and storage: findings from a structured expert elicitation', International Journal of Risk Assessment and Management, forthcoming.

Larkin, P., Leiss, W. and Krewski, D. (2019c) 'Risk management frameworks for carbon capture and storage: a global perspective', International Journal of Risk Assessment and Management, forthcoming.

Larkin, P., Leiss, W., Arvai, J., Gracie, R. G., Fall, M., Dusseault, M. D., Heyes, A. and Krewski, D. (2019d) 'An integrated risk management framework for carbon capture and storage in the Canadian context', International Journal of Risk Assessment and Management, forthcoming.

Lavoie, R. and Keith, D. (2010) Executive Summary of Wabamun Area $\mathrm{CO}_{2}$ Sequestration Project $(W A S P)$, University of Calgary Institute for Sustainable Energy, Environment and Economy (ISEEE), Calgary.

Lawton, D. et al. (2010) Recommendations for Injection and Storage Monitoring, Wabamun Area $\mathrm{CO}_{2}$ Sequestration Project (WASP), Institute for Sustainable Energy, Environment and Economy (ISEEE), University of Calgary, Calgary.

Le Guénana, T., Manceaua, J-C., Bouca, O. and Rohmera, J. (2011) 'GERICO: a database for $\mathrm{CO}_{2}$ geological storage risk management', Energy Procedia., Vol. 4, pp.4124-4131, doi.org/10.1016/j.egypro.2011.02.356.

Leiss, W. (2009) Risk Management of Carbon Capture and Storage: Overview and Future Steps, McLaughlin Centre for Population Health Risk Assessment, Prepared for Institute for Sustainable Energy, Environment, and Economy, University of Calgary, Ottawa, ON.

Linkov, I., Satterstrom, F.K., Kiker, G., Batchelor, C., Bridges, T. and Ferguson, E. (2006) 'From comparative risk assessment to multi-criteria decision analysis and adaptive management: recent developments and applications', Environment International, Vol. 32, No. 8, pp.1072-1093.

Liu, F., Lu, P., Griffith, C., Hedges, S.W., Soong, Y., Hellevangc, H. and Zhu, C. (2012) $\mathrm{CO}_{2}$-brine-caprock interaction: Reactivity experiments on Eau Claire shale and a review of relevant literature', International Journal of Greenhouse Gas Control, March, March, Vol. 7, pp.152-167. 
Liu, X., Godbole, A., Lu, C. and Michal, G. (2017) 'Investigation of terrain effects on the consequence distance of $\mathrm{CO}_{2}$ released from high-pressure pipelines', International Journal of Greenhouse Gas Control, November, Vol. 66, pp.264-275.

Massachusetts Institute of Technology (MIT) (2012) Project Pioneer Fact Sheet: Carbon Dioxide Capture and Storage Project [online] http://sequestration.mit.edu/tools/projects/transalta.html (accessed 2012).

Mazzoldi, A., Rinaldi, A.P., Borgia, A. and Rutqvist, J. (2012) 'Induced seismicity within geological carbon sequestration projects: maximum earthquake magnitude and leakage potential from undetected faults', International Journal of Greenhouse Gas Control , September, Vol. 10, pp.434-442.

Mocellin, P., Vianello, C., Salzano, E., and Maschio, G. (2018) 'Pressurized $\mathrm{CO}_{2}$ releases in the framework of carbon sequestration and enhanced oil recovery safety analysis: experiments and model', Process Safety and Environmental Protection, May, Vol. 116, pp.433-449.

Newmark, R., Friedmann, S. and Carroll, S. (2010) 'Water challenges for geologic carbon capture and sequestration', Environmental Management, Vol. 45, No. 4, pp.651-661.

Nicot, J-P. and Duncan, I.J. (2012) 'Common attributes of hydraulically fractured oil and gas production and $\mathrm{CO}_{2}$ geological sequestration', Greenhouse Gas Science and Technology, Vol. 2, No. 5, pp.352-368.

Nygaard, R. (2010) Well Design and Well Integrity, Wabamun Area $\mathrm{CO}_{2}$ Sequestration Project $(W A S P)$, University of Calgary Institute for Sustainable Energy, Environment and Economy (ISEEE), Calgary.

Preston, C., Monea, M., Jazrawet, W. et al. (2005) 'IEA GHG Weyburn $\mathrm{CO}_{2}$ monitoring and storage project', Fuel Processing Technology, Vol. 86, Nos. 14-15, pp.1547-1568.

Puress, K. and Garcia, J. (2002) 'Multiphase flow dynamics during $\mathrm{CO}_{2}$ disposal into saline aquifers', Environmental Geology, Vol. 42, Nos. 2-3, pp.282-295.

Quintessa (2012) Generic $\mathrm{CO}_{2}$ FEP Database, Version 1.1.0 [online] http://www.quintessaonline.com/fep.php [accessed 2012].

Seto, C.J. and McRae, G.J. (2011) 'Reducing risk in basin scale sequestration, a Bayesian model selection framework for improving detection', Energy Procedia, Vol. 4, pp.4199-4206.

Shell Canada Limited (2010a) Quest Carbon Capture and Storage Project Environmental Assessment [online] https://www.shell.ca/en_ca/about-us/projects-and-sites/quest-carboncapture-and-storage-project.html (accessed 5 January 2013).

Shell Canada Limited (2010b) Quest Carbon Capture and Storage Project, Volume $2 \mathrm{~A}$ and $2 \mathrm{~B}$ : Project Description [online] http://s02.static-shell.com/content/dam/shell-new/local/country/ can/downloads/pdf/aboutshell/our-business/oil-sands/quest/quest-vol-2a-compiled.pdf (accessed 28 August 2018).

Shell Canada Limited (2010c) Quest Carbon Capture and Storage Project, Volume 1: Project Description, Appendix A: Measurement, Monitoring and Verification Plan [online] http://s04.static-shell.com/content/dam/shell-new/local/country/can/downloads/pdf/aboutshell/ our-business/oil-sands/quest/02-quest-vol-1-appxammvplan.pdf (accessed 28 August 2018).

Shell Canada Limited (2011a) Quest Carbon Capture and Storage Project, Response to Request for Additional Information from ERCB, November 30, 2011, Application No. 1670112, available through Alberta Energy Regulator request for information.

Shell Canada Limited (2011b) Quest Carbon Capture and Storage Project, Quantitative Risk Assessment: $\mathrm{CO}_{2}$ Pipeline and Injection Wells [online] https://www.shell.ca/en_ca/aboutus/projects-and-sites/quest-carbon-capture-and-storage-project.html (accessed 5 January 2013).

Shell Canada Limited (2011c) Quest Carbon Capture and Storage Project, Response to Supplemental Information Request \#2, November [online] http://s00.static-shell.com/content/ dam/shell-new/local/country/can/downloads/pdf/aboutshell/our-business/oil-sands/quest/sirsresponses-2nov11.pdf (accessed 28 August 2018). 
US Department of Energy (2007) FutureGen Project Final Environmental Impact Statement, National Energy Technology Laboratory [online] https://www.energy.gov/nepa/listings/eis0394-documents-available-download (accessed 21 July 2019).

US Department of Energy (2013) FutureGen 2.0 Project, Draft Environmental Impact Statement, National Energy Technology Laboratory [online] [online] https://www.energy.gov/sites/prod/ files/2013/04/f0/EIS-0460-DEIS-Volume_I-2013.pdf (accessed 21 July 2019).

Verdon, J., Kendall, J.-M., White, D.J., Angus, D.A., Fisher, Q.J. and Urbancic, T. (2010) 'Passive seismic monitoring of carbon dioxide storage at Weyburn', The Leading Edge, February, Vol. 29, No. 2, pp.200-206.

Walton, F.B., Tait, J.C., LeNeveu, D. and Sheppard, M.I. (2004) 'Geological storage of $\mathrm{CO}_{2}$ : a statistical approach to assessing performance and risk', Proc. 7th International Conference on Greenhouse Gas Control Technologies, Vancouver, Canada, VI, pp.693-700, Elsevier Science Ltd.

Wilday, J., Moonis, M., Wardman, M. and Johnson, M. (2009) Safety in Carbon Dioxide Capture, Transport and Storage, Prepared for Executive Committee of IEA Greenhouse Gas RandD Programme - IEA-GHG.

Wilday, J., Wardman, M., Johnson, M. and Haines, M. (2011) 'Hazards from carbon dioxide capture, transport and storage', Process Safety and Environmental Protection, Vol. 89, No. 6, pp.482-491.

Williams, B.K., Brown, E.D. et al. (2012) Adaptive Management, US Department of the Interior Applications Guides, $\mathrm{x}+120 \mathrm{pp}$, ISBN 978-0-615-59913-7.

Wilson, M. and Monea, M. (2004) 'IEA GHG Weyburn $\mathrm{CO}_{2}$ monitoring and storage project summary report 2000-2004', Proc. 7th International Conference on Greenhouse Gas Control Technologies., Vancouver, Canada, V III, Elsevier Science Ltd. (2005) (original report published by the Petroleum Technology Research Center, Regina, Saskatchewan).

Zoback, M.D. and Gorelick, S.M. (2012) 'Earthquake triggering and large-scale geologic storage of carbon dioxide', Publications of the National Academy of Sciences, Vol. 109, No. 26, pp.10164-10168. 